\title{
Two-photon Absorption (TPA) Spectra of Tris(4,7-diphenyl-1,10-phenanthroline)metal(II) Perchlorate: Drastic Effects of Central Metal(II) Ions on TPA Cross Section
}

\author{
Hiroki Moritomo, ${ }_{1}^{1}$ Kenta Nakagawa, ${ }^{1}$ Hiroyuki Sugihara, ${ }^{2}$ Yasutaka Suzuki, ${ }^{1}$ and Jun Kawamata ${ }^{* 1}$ \\ ${ }^{1}$ Graduate School of Medicine, Yamaguchi University, 1677-1 Yoshida, Yamaguchi 753-8512 \\ ${ }^{2}$ Graduate School of Science and Engineering, Yamaguchi University, 1677-1 Yoshida, Yamaguchi 753-8512
}

(E-mail: j_kawa@yamaguchi-u.ac.jp)

Two-photon absorption (TPA) spectra were measured on a dimethyl sulfoxide solution of $\left[\mathrm{M}(\mathrm{dpphen})_{3}\right]\left(\mathrm{ClO}_{4}\right)_{2}$ (dpphen: 4,7-diphenyl-1,10-phenanthroline; $\mathrm{M}=\mathrm{Mn}, \mathrm{Co}, \mathrm{Ni}, \mathrm{Cu}, \mathrm{Zn}$, and $\mathrm{Ru}$ ). The TPA cross section depended drastically on the central metal(II) ions, in the order $\mathrm{Ru}-\gg \mathrm{Co}->\mathrm{Ni}->\mathrm{Mn}->$ $\mathrm{Cu}->\mathrm{Zn}$ complexes. The effects were rationalized in terms of the resonance of photons used for two-photon transition with one-photon absorption band.

Two-photon absorption (TPA) takes place when a material simultaneously absorbs two photons. Because the absorption intensity is proportional to the square of the intensity of an incident beam, a focal point could be excited exclusively by using a tightly focused laser beam. This leads to the characteristic three-dimensional (3D) spatial selectivity in excitation. The properties are utilized to develop optical devices such as 3D optical data storage, ${ }^{1}$ 3D microfabrication, ${ }^{2}$ 3D fluorescence microscopy, ${ }^{3}$ and 3D photodynamic therapy. ${ }^{4}$ The transition probability of TPA is quite low; therefore, an intense light source such as a femtosecond pulsed laser is required to apply TPA to such applications. The comprehensive exploration of efficient TPA materials with large TPA cross sections $\left(\sigma^{(2)}\right)$ is being pursued during the last two decades. ${ }^{5}$

According to the perturbation expansion theory, ${ }^{6}$ the peak of $\sigma^{(2)}$ at the lowest-energy TPA transition $\left(\sigma_{\text {peak }}^{(2)}\right)$ can be expressed as

$$
\sigma_{\text {peak }}^{(2)} \propto \frac{\left|\mu_{k g}\right|^{2}\left|\mu_{e k}\right|^{2}}{\Delta E^{2} \Gamma_{e g}} E_{e g}^{2}
$$

where $\mu_{k g}$ denotes the transition dipole moment from the ground state $(g)$ to the lowest one-photon absorption-allowed energy level $(k), \mu_{e k}$ is the transition dipole moment from $k$ to the lowest TPA-allowed energy level $(e), E_{e g}$ is the energy gap between $g$ and $e, \Gamma_{e g}$ is a damping factor, and $\Delta E$ is the resonance term also called the detuning energy, which is equal to the difference between the energy gap from $g$ to $k$ and the photon energy of the two-photon excitation, $\Delta E=\left(E_{k g}-E_{e g} / 2\right)$. According to eq 1 , a compound with a large transition dipole moment and/or a small $\Delta E$ is expected to exhibit large $\sigma_{\text {peak }}^{(2)}$. Enhancement of the transition dipole moment is a popular strategy for increasing $\sigma_{\text {peak }}^{(2)} \cdot{ }^{7}$ The introduction of electron donor or acceptor groups at the ends of a $\pi$-conjugated system is widely used for this purpose. ${ }^{8}$ Another effective strategy for obtaining molecules with large transition dipole moments is to extend the planarity of the $\pi$-conjugated system. ${ }^{9}$ For organic compounds, there is no established means for tuning $E_{k g}$ and $E_{e g}$ independently. Only one example reported to decrease $\Delta E$ is the incorporation of azulenyl moiety in a $\pi$-conjugated system. ${ }^{10}$ Azulene derivatives possess an additional weak absorption band at a longer wavelength region in addition to the main absorption band. An intense TPA band of a typical organic compound containing the azulene derivatives is located near the main absorption band. Therefore, the photon energy used to the twophoton excitation to the intense TPA band is close to that of the additional one-photon absorption band. This results in small $\Delta E$ and accordingly large $\sigma_{\text {peak }}^{(2)}$.

For typical transition-metal complexes, their absorption spectra consist of the main intense absorption band attributed to the $\pi-\pi^{*}$ transition of ligands and the additional absorption band attributed to MLCT, LMCT, or d-d transition. In most cases, the additional band is located at the wavelength region longer than that of $\pi-\pi^{*}$ band. ${ }^{11}$ We noted that such a situation is similar to the case of the azulene derivatives. Therefore, these metal complexes are expected to exhibit small $\Delta E$. Moreover, in contrast to the difficulty in tuning $E_{k g}$ and $E_{e g}$ independently for organic compounds, the use of metal complexes might provide a novel strategy for designing a molecule with small $\Delta E$. This is because the transition energy related to a free ligand is scarcely affected by the coordination with a metal ion, while the transition energy intrinsic to a metal ion remains nearly at the same level even when a coordinated ligand is varied. These situations might enable us to tune the two transition bands independently.

So far no systematic spectroscopic experiment has been performed for metal complexes to clarify the resonance effects on TPA properties, though there are several reports on the TPA properties of metal complexes. ${ }^{12-14}$ To develop a novel strategy for enhancing $\sigma^{(2)}$, we have synthesized metal complexes comprising the same ligands but different central metal ions. The investigated complexes were tris(4,7-diphenyl-1,10-phenanthroline)metal(II) perchlorate (denoted as $\left[\mathrm{M}(\mathrm{dpphen})_{3}\right]\left(\mathrm{ClO}_{4}\right)_{2}$; dpphen: 4,7-diphenyl-1,10-phenanthroline; $\mathrm{M}=\mathrm{Mn}, \mathrm{Co}, \mathrm{Ni}$, $\mathrm{Cu}, \mathrm{Zn}$, and $\mathrm{Ru}$; Figure 1). For a series of complexes, the effect of resonance properties on $\sigma^{(2)}$ was studied systematically by the Z-scan technique. ${ }^{15}$

Figure 2 shows the absorption spectra of $\left[\mathrm{Ru}(\mathrm{dpphen})_{3}\right]-$ $\left(\mathrm{ClO}_{4}\right)_{2}$ and free dpphen in dimethyl sulfoxide. In the absorption spectrum of free dpphen, a peak attributed to $\pi-\pi^{*}$ transition was observed at $320 \mathrm{~nm}$. On the other hand, $\left[\mathrm{Ru}(\mathrm{dpphen})_{3}\right]\left(\mathrm{ClO}_{4}\right)_{2}$ possessed two peaks at 320 and $450 \mathrm{~nm}$, which were attributed to the $\pi-\pi^{*}$ and MLCT transitions, respectively.

Figure 3 shows the TPA spectra of $\left[\mathrm{Ru}(\mathrm{dpphen})_{3}\right]\left(\mathrm{ClO}_{4}\right)_{2}$ and dpphen in dimethyl sulfoxide. For $\left[\mathrm{Ru}(\mathrm{dpphen})_{3}\right]\left(\mathrm{ClO}_{4}\right)_{2}$, $\sigma^{(2)}$ was found to increase with the decrease in the wavelength shorter than $600 \mathrm{~nm}$. This was attributed to the double 


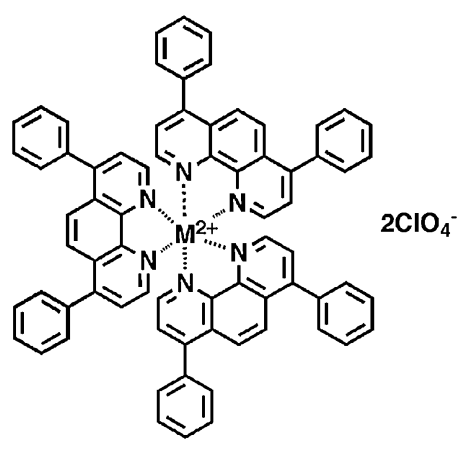

Figure 1. The molecular structure of $\left[\mathrm{M}(\text { dpphen })_{3}\right]\left(\mathrm{ClO}_{4}\right)_{2}$ $(\mathrm{M}=\mathrm{Mn}, \mathrm{Co}, \mathrm{Ni}, \mathrm{Cu}, \mathrm{Zn}$, and $\mathrm{Ru})$.

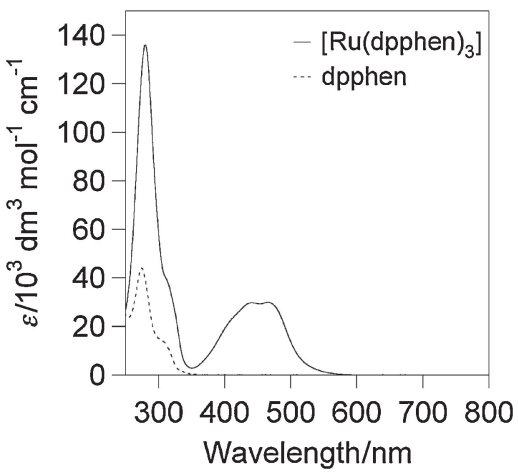

Figure 2. Absorption spectra of $\left[\mathrm{Ru}(\mathrm{dpphen})_{3}\right]\left(\mathrm{ClO}_{4}\right)_{2}$ and dpphen in dimethyl sulfoxide $\left(10^{-3} \mathrm{~mol} \mathrm{dm}^{-3}\right)$.

resonance ${ }^{16}$ of photon used for two-photon excitation with the MLCT band. The maximum $\sigma^{(2)}$ value was observed to be $271 \mathrm{GM}\left(1 \mathrm{GM}=10^{-50} \mathrm{~cm}^{4}\right.$ s photon $^{-1}$ molecule $\left.^{-1}\right)$ at $570 \mathrm{~nm}$. The value of $\sigma_{\text {peak }}^{(2)}$ was observed to be $115 \mathrm{GM}$ at $800 \mathrm{~nm}$, which was close to the double wavelength of the MLCT band in the one-photon absorption spectrum. This was a typical transition to a TPA-allowed state located near the MLCT band. It is well known that the structure-property relationship of the compounds can be discussed more clearly with $\sigma_{\text {peak }}^{(2)} \cdot{ }^{10}$ Therefore, first, let us discuss about $\sigma_{\text {peak; }}^{(2)}$

For dpphen, $\sigma_{\text {peak }}^{(2)}$ was found to be $10 \mathrm{GM}$ at $570 \mathrm{~nm}$, which was close to the double wavelength of the $\pi-\pi^{*}$ band. Using eq 1 , it was found that $\sigma_{\text {peak }}^{(2)}$ is proportional to the square of $\mu_{\mathrm{kg}}$ and $\mu_{e k}$. The value of $\mu_{\mathrm{kg}}{ }^{2}$ is proportional to the oscillator strength $(f)$ of the one-photon absorption band. Because there is no means for predicting $\mu_{e k}$, the relation of $\mu_{k g} \propto \mu_{e k}$ or $\sigma_{\text {peak }}^{(2)} \propto f^{2}$ is assumed as conventionally done for the cases of organic compounds. Such assumption has been proved to explain well the experimental results of organic compounds. ${ }^{6}$ In the present cases, the $f$ values of the $\pi-\pi^{*}$ transition of dpphen and the MLCT transition of $\left[\mathrm{Ru}(\mathrm{dpphen})_{3}\right]\left(\mathrm{ClO}_{4}\right)_{2}$ were obtained to be 0.51 and 0.32 , respectively. When the relation of $\sigma_{\text {peak }}^{(2)} \propto f^{2}$ was assumed together with the decrease in $\Delta E$ due to the energy difference of one- and two-photon transitions, the $\sigma_{\text {peak }}^{(2)}$ value related to the MLCT of $\left[\mathrm{Ru}(\text { dpphen })_{3}\right]\left(\mathrm{ClO}_{4}\right)_{2}$ was calculated to be 0.5 times smaller than that of dpphen related to the $\pi-\pi^{*}$ transition. However, the experimental $\sigma_{\text {peak }}^{(2)}$ of $\left[\mathrm{Ru}(\mathrm{dpphen})_{3}\right]\left(\mathrm{ClO}_{4}\right)_{2}$ was 12 times larger than that of dpphen.

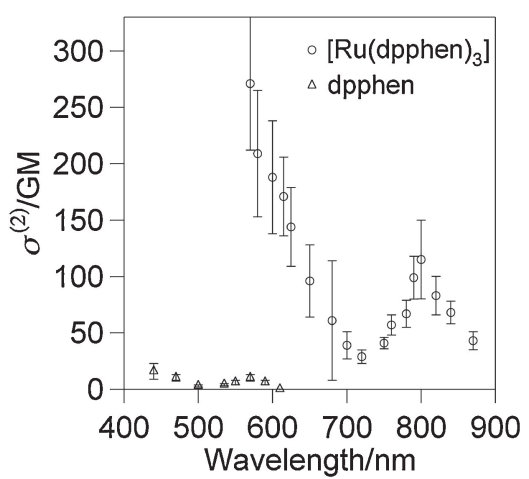

Figure 3. Two-photon absorption spectra of $\left[\mathrm{Ru}(\mathrm{dpphen})_{3}\right]-$ $\left(\mathrm{ClO}_{4}\right)_{2}\left(10^{-3} \mathrm{~mol} \mathrm{dm}^{-3}\right)$ and dpphen $\left(0.1 \mathrm{~mol} \mathrm{dm}^{-3}\right)$ in dimethyl sulfoxide.

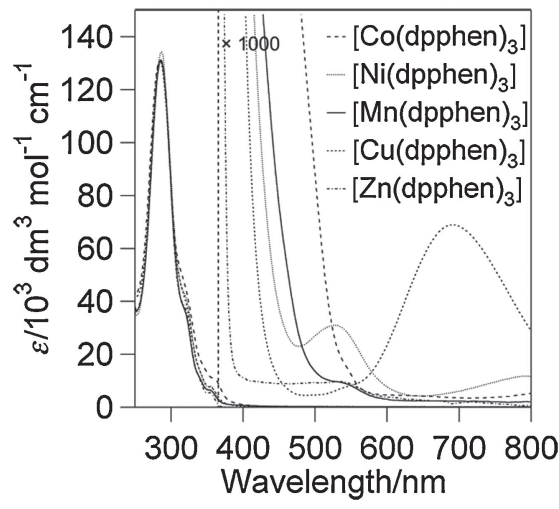

Figure 4. Absorption spectra of $\left[\mathrm{M}(\text { dpphen })_{3}\right]\left(\mathrm{ClO}_{4}\right)_{2} \quad(\mathrm{M}=$ $\mathrm{Mn}, \mathrm{Co}, \mathrm{Ni}, \mathrm{Cu}$, and $\mathrm{Zn})$ in dimethyl sulfoxide $\left(10^{-3} \mathrm{~mol} \mathrm{dm}^{-3}\right)$. The spectra were magnified by 1000 times in the region of 350 to $800 \mathrm{~nm}$.

This fact suggested that the $\mu_{e k}$ due to MLCT transition was much larger than that of $\pi-\pi^{*}$ transition.

Figure 4 shows the absorption spectra of [M(dpphen $\left.)_{3}\right]$ $\left(\mathrm{ClO}_{4}\right)_{2}(\mathrm{M}=\mathrm{Mn}, \mathrm{Co}, \mathrm{Ni}, \mathrm{Cu}$, and $\mathrm{Zn})$ in dimethyl sulfoxide. The molar absorption coefficients at $350 \mathrm{~nm}$ due to the $\pi-\pi^{*}$ transition of dpphen were almost the same as those of $\left[\mathrm{Ru}(\mathrm{dpphen})_{3}\right]\left(\mathrm{ClO}_{4}\right)_{2}$. On the other hand, those of additional bands located in the visible wavelength region, which were attributed to the $\mathrm{d}-\mathrm{d}$ transitions, were more than 100 times smaller than that of MLCT transition of $\left[\mathrm{Ru}(\mathrm{dpphen})_{3}\right]\left(\mathrm{ClO}_{4}\right)_{2}$.

Figure 5 shows the TPA spectra of $\left[\mathrm{M}(\text { dpphen })_{3}\right]\left(\mathrm{ClO}_{4}\right)_{2}$ $(\mathrm{M}=\mathrm{Mn}, \mathrm{Co}, \mathrm{Ni}, \mathrm{Cu}$, and $\mathrm{Zn})$ in dimethyl sulfoxide. The measurements were performed in the wavelength region shorter than $850 \mathrm{~nm}$. Although $\sigma_{\text {peak }}^{(2)}$ attributed to the d-d transition was expected to be located in the wavelength region $1000-1500 \mathrm{~nm}$, the $\sigma_{\text {peak }}^{(2)}$ would be very small, considering the small molar absorption coefficients of the $\mathrm{d}-\mathrm{d}$ transition. Such small $\sigma_{\text {peak }}^{(2)}$ in the infrared region are substantially interfered by the presence of the vibration bands of solvents. Therefore, we did not measure $\sigma^{(2)}$ in the wavelength region above $850 \mathrm{~nm}$.

As shown in Figure 5, $\sigma^{(2)}$ increased monotonously with the decrease in wavelength, except for $\left[\mathrm{Cu}(\mathrm{dpphen})_{3}\right]\left(\mathrm{ClO}_{4}\right)_{2}$. The $\mathrm{Cu}$ complex exhibited an absorption peak at $700 \mathrm{~nm}$, which was almost equal to the wavelength of the one-photon absorption 


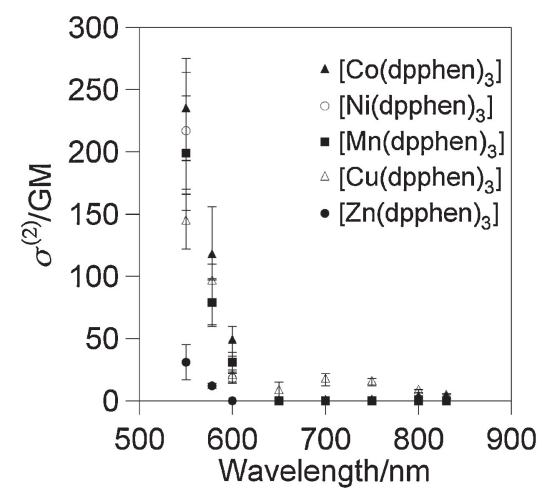

Figure 5. Two-photon absorption spectra of $\mathrm{Mn}-, \mathrm{Co}-, \mathrm{Ni}-$, $\mathrm{Cu}-$, and $\mathrm{Zn}$ complexes in dimethyl sulfoxide $\left(10^{-3} \mathrm{~mol} \mathrm{dm}^{-3}\right)$.

Table 1. Two-photon absorption cross-section $\left(\sigma^{(2)}\right)$, the wavelengths of one-photon absorption peaks $\left(\lambda_{\max }\right)$ of $\mathrm{d}-\mathrm{d}$ band and the cutoff wavelength of $\mathrm{Mn}-, \mathrm{Co}-, \mathrm{Ni}-, \mathrm{Cu}-, \mathrm{Zn}-$, and $\mathrm{Ru}$ complexes

\begin{tabular}{ccccc}
\hline \multirow{2}{*}{$\begin{array}{c}\text { Center } \\
\text { metal }\end{array}$} & at $550 \mathrm{~nm}$ & at $570 \mathrm{~nm}$ & $\begin{array}{c}\lambda_{\max } \text { of } \\
\mathrm{d}-\mathrm{d} \text { band } \\
/ \mathrm{nm}\end{array}$ & $\begin{array}{c}\text { Cutoff } \\
\text { wavelength } \\
/ \mathrm{nm}\end{array}$ \\
\cline { 2 - 5 } $\mathrm{Ru}$ & $-^{\mathrm{a}}$ & 271 & no d-d band & $530^{\mathrm{b}}$ \\
$\mathrm{Co}$ & 234 & 117 & 545 & 530 \\
$\mathrm{Ni}$ & 217 & 79 & 530 & 455 \\
$\mathrm{Mn}$ & 199 & 79 & 540 & 475 \\
$\mathrm{Cu}$ & 144 & 96 & 685 & 430 \\
$\mathrm{Zn}$ & 31 & 12 & 540 & 385 \\
\hline
\end{tabular}

${ }^{a}$ Owing to an intense one-photon absorption, $\sigma^{(2)}$ could not be determined at this wavelength. ${ }^{\mathrm{b}}$ Cutoff wavelength related to the MLCT band.

peak of the $\mathrm{d}-\mathrm{d}$ band. Therefore, the origin of the peak of $\sigma^{(2)}$ can be attributed to the resonance to the $\mathrm{d}-\mathrm{d}$ transition. The maximum value of $\sigma^{(2)}$ of the $\mathrm{Zn}$ complex was almost three times as large as that of ligands. Based on this, the absorption is thought to be originated from the three ligands attached to a $\mathrm{Zn}$ ion. As for other complexes, however, the $\sigma^{(2)}$ values were considerably larger than that of the $\mathrm{Zn}$ complex. The $\sigma^{(2)}$ value at $550 \mathrm{~nm}$ followed the order $\mathrm{Co}->\mathrm{Mn}->\mathrm{Ni}->\mathrm{Cu}->\mathrm{Zn}$ complexes. This order was thought to reflect the contribution of the resonance enhancement. ${ }^{16}$

Table 1 summarizes the values of $\sigma^{(2)}$ as obtained for a series of $\left[\mathrm{M}(\text { dpphen })_{3}\right]\left(\mathrm{ClO}_{4}\right)_{2}(\mathrm{M}=\mathrm{Mn}, \mathrm{Co}, \mathrm{Ni}, \mathrm{Cu}, \mathrm{Zn}$, and $\mathrm{Ru}$ ), the wavelengths of one-photon absorption peaks of $\mathrm{d}-\mathrm{d}$ transitions and the cutoff wavelengths of main absorption bands determined by extrapolating the steepest tangent in the onephoton absorption curve ignoring the $\mathrm{d}-\mathrm{d}$ band. The cutoff wavelength decreased in the order $\mathrm{Co}->\mathrm{Mn}->\mathrm{Ni}->\mathrm{Cu}->$ $\mathrm{Zn}$ complexes. Although the cutoff wavelength of Mn complex was longer than that of $\mathrm{Ni}$ complex, the $\sigma^{(2)}$ value at $550 \mathrm{~nm}$ of $\mathrm{Mn}$ complex was smaller than that of $\mathrm{Ni}$ complex. The $\mathrm{Ni}$ complex exhibited a small absorption peak at $530 \mathrm{~nm}$. Therefore, not only the resonance to the edge of the main absorption band but also the resonance to the transition at $530 \mathrm{~nm}$ should be operated in the TPA transition of Ni complex at $550 \mathrm{~nm}$. When the resonant TPA behavior of these complexes was compared with that of Ru complex at $570 \mathrm{~nm}$, the Ru complex exhibited the extremely large $\sigma^{(2)}$ value among the investigated six complexes. This should be attributed to the large transition dipole moment of the resonant MLCT transition band. Because the Ru complex exhibits photoluminescence, we have confirmed the applicability of the complex to practical $3 \mathrm{D}$ imaging using a two-photon fluorescence microscope. As a result, a clear 3D image of a living cell stained with the Ru complex has actually been obtained.

In summary, the resonant two-photon transition was enhanced under the following two conditions: (1) the energy of the photon used for two-photon transition was close to the nearest one-photon absorption band ( $\Delta E$ is made small), and (2) the molar absorption coefficient of the nearest one-photon absorption transition was large. Thus, the wavelengths and the transition dipole moments of the absorption bands originating from ligands or metal ions ( $d-d$, MLCT, or LMCT) should be designed independently to satisfy the above two conditions. It is also suggested that the MLCT transition is possibly more effective to $\sigma^{(2)}$ than the $\pi-\pi^{*}$ transition. The quite large $\sigma^{(2)}$ would be obtained when a metal complex with an intense MLCT transition is designed. ${ }^{17}$

\section{References and Notes}

1 D. A. Parthenopoulos, P. M. Rentzepis, Science 1989, $245,843$.

2 S. Maruo, O. Nakamura, S. Kawata, Opt. Lett. 1997, 22, 132.

3 W. Denk, J. H. Strickler, W. W. Webb, Science 1990, 248, 73.

4 J. D. Bhawalkar, N. D. Kumar, C.-F. Zhao, P. N. Prasad, J. Clin. Laser Med. Surg. 1997, 15, 201.

5 M. Pawlicki, H. A. Collins, R. G. Denning, H. L. Anderson, Angew. Chem., Int. Ed. 2009, 48, 3244.

6 M. Rumi, J. E. Ehrlich, A. A. Heikal, J. W. Perry, S. Barlow, Z. Hu, D. McCord-Maughon, T. C. Parker, H. Röckel, S. Thayumanavan, S. R. Marder, D. Beljonne, J.-L. Brédas, J. Am. Chem. Soc. 2000, 122, 9500.

7 K. Ogawa, A. Ohashi, Y. Kobuke, K. Kamada, K. Ohta, J. Phys. Chem. B 2005, 109, 22003.

8 M. Albota, D. Beljonne, J.-L. Brédas, J. E. Ehrlich, J.-Y. Fu, A. A. Heikal, S. E. Hess, T. Kogej, M. D. Levin, S. R. Marder, D. McCord-Maughon, J. W. Perry, H. Röckel, M. Rumi, G. Subramaniam, W. W. Webb, X.-L. Wu, C. Xu, Science 1998, $281,1653$.

9 J. Kawamata, M. Akiba, Y. Inagaki, Jpn. J. Appl. Phys. 2003, 42, L17.

10 S. Hirakawa, J. Kawamata, Y. Suzuki, S. Tani, T. Murafuji, K. Kasatani, L. Antonov, K. Kamada, K. Ohta, J. Phys. Chem. A 2008, 112, 5198.

11 P. Day, N. Sanders, J. Chem. Soc. A 1967, 1536.

12 J. R. Lakowicz, F. N. Castellano, I. Gryczynski, Z. Gryczynski, J. D. Dattelbaum, J. Photochem. Photobiol., A 1999, 122, 95.

13 S. K. Hurst, M. G. Humphrey, T. Isoshima, K. Wostyn, I. Asselberghs, K. Clays, A. Persoons, M. Samoc, B. LutherDavies, Organometallics 2002, 21, 2024.

14 B. J. Coe, M. Samoc, A. Samoc, L. Zhu, Y. Yi, Z. Shuai, J. Phys. Chem. A 2007, 111, 472.

15 M. Sheik-Bahae, A. A. Said, T.-H. Wei, D. J. Hagan, E. W. Van Stryland, IEEE J. Quantum Electron. 1990, 26, 760.

16 K. Kamada, K. Ohta, Y. Iwase, K. Kondo, Chem. Phys. Lett. 2003, 372, 386 .

17 Supporting Information is available electronically on the CSJJournal Web site, http://www.csj.jp/journals/chem-lett/index. html. 